\title{
INSIDER RESEARCH: REPRESENTING PERIPHERAL VOICES AND MULTIPLE IDENTITIES WHEN WRITING ABOUT PERSONAL TRAUMA
}

\author{
Leanne Dodd | CQUniversity
}

\begin{abstract}
As an 'insider' researcher writing about personal trauma, I sought to reconcile my multiple identities in my doctoral thesis: scholar/researcher, creative writing practitioner, and trauma survivor evolving from the process of writing about trauma. Concerns arose about how I could insert these peripheral voices and multiple identities into my creative thesis, while paying attention to the tenets of scholarly rigour and my desire for creativity. This article presents a case study of the design of my thesis, where my research endeavour was to 're-story' my self-narrative through ficto-memoir: a creative writing process whereby my personal experiences were fictionalised, but carried the same emotional affect and benefits as writing about real experiences. This article contends that creativity could still be achieved in a conventional academic thesis structure with a slightly modified format that allows for the insertion of an author's parallel voices into the research and alignment with the creative work.
\end{abstract}

BIOGRAPHICAL NOTE

Leanne Dodd has multiple identities, as an author, an early career researcher, a university lecturer, and a writing mentor. She completed her $\mathrm{PhD}$ in creative writing in 2018, which investigated the benefits of fictionalising traumatic experience. Her practice-led PhD novel was long-listed for the 2018 Richell Prize with Hachette publishers and the 2019 Adaptable program with Screen Queensland/Queensland Writers Centre.

KEYWORDS

Trauma Writing-Writing Identity-Scholarly Rigour-Creative Thesis 
Much attention has been drawn to the validity of 'insider research' where the researcher identifies as a member of the group being studied (Ross 2017), but what of the insider researcher who is simultaneously the subject of the study? My endeavour in my doctoral project was to research the process of 're-storying' my self-narrative through ficto-memoir, a creative writing process drawing from narrative therapy, whereby my personal experiences were partially fictionalised but carried the same emotional affect and benefits as writing about real experiences. This cross-disciplinary approach sought to determine whether the writing process provided catharsis, reconnection, or generated empathetic understanding. While trauma is naturally enmeshed in narrative, trauma theorists have established that a traumatic event cannot become a narrative memory until it is integrated into a complete story-and this is denied by the patchy nature of memories (Caruth 1995: 153). My project investigated the narrative strategies used to integrate these patchy memories into a complete story using ficto-memoir, while also examining the evolution of three coexisting identities in the exegesis: scholar/researcher, creative writing practitioner, and trauma survivor evolving from the process of writing about trauma.

Since the self is involved in trauma in extremis, there were perils in engaging in this type of insider research that encroached upon my personal issues of traumatic experience and fractured identity and how this might impact my authorial voice in the exegesis. Drake (2010) cautions that to achieve validity in insider research there should be some degree of reflexivity and consideration of the researcher's position, particularly with respect to how their motivation might impact the reporting of the data. My initial concerns, not unlike that of many other creative writing practitioners embarking on a research degree, were that my co-existing identities of creative writing practitioner and trauma survivor might become peripheral to the voice of the scholar/researcher. Hence, my motivation and subsequent potential for bias could well prove to be an issue in the context of Drake's cautionary advice.

Framed within an evolving doctoral landscape, this article explores the implications of placing myself 'inside' the research using my practice-led doctoral project as a case study. The question raised is how I could insert my peripheral voices and multiple identities into my creative thesis, while paying attention to the tenets of rigour and the desire for creativity. I address this question by firstly posing strategies for assuring scholarly rigour in the creative writing research methodology. I then propose approaches for the design of a self-reflective exegesis, through the consideration of writing identity and experimentation in a form that might prove helpful for others.

\section{Scholarly Rigour}

In the context of qualitative research, the term 'rigour' has been used to refer to the 'reliability and validity of research' (Davies and Dodd 2002: 280), assessment of trustworthiness (Schwandt, Lincoln and Guba 2007), and protection against bias to enhance the reliability of findings (Mays and Pope 1995: 109). All these definitions indicate that the rigour of a research study may come into question at any time that the researcher is perceived to be affiliated with, or part of, the study's population. Gerhard asserts that 'investigators should aim to avoid bias in the design of a study [or] 
adjust for bias in the study analysis if bias cannot feasibly be avoided' (2008: 2167). Reflecting on my project, I was attempting to insert multiple voices into my research: the authorial scholar and researcher, the creative writer and provider of 'insider' traumatic subject matter to be fictionalised, and the test subject to determine whether the writing process provided mental health benefits. Milech and Schilo argue that 'research students should not be positioned to be their own critics, reviewers or commentators' (2004: 6), so the issue of bias was compounded by the fact that the population of this research study was confined solely to me. The insertion of myself into the research led to concerns by supervisors and the academic committee approving my project as to whether my subjective opinion could be biased and whether this compromised the integrity of the data. Chenail also proposes that while qualitative researchers can 'become the instruments through which data for their studies are collected or generated...mental and other discomfort could pose a threat to data' (2011: 255). The committee were also concerned about my welfare and how I would manage possible re-traumatisation.

In resolving these concerns about rigour, I leaned toward Guba's 'parallel criteria of trustworthiness' (Schwandt, Lincoln and Guba 2007: 18) model for assessing the rigour of qualitative data, which has received support in academic health research and seemed relevant to my cross-disciplinary motivations. Guba's four 'parallel criteria of trustworthiness' for qualitative research respond to four basic questions of rigour originating in conventional research paradigms: credibility (internal validity); transferability (external validity); dependability (reliability); and confirmability (objectivity). Not all of Guba's tests fit my objectives, but the following have been applied as a guide to how insider researchers, particularly those dealing with trauma, may adapt their research to strengthen rigour.

The first test for credibility is prolonged engagement, which measures how long the researcher has engaged with the phenomena in the field to test that there is a credible amount of data from which to identify saliencies. I had a wealth of personal experience from which to draw my data to satisfy this test. The experiences of trauma (the phenomena) fictionalised in my project, resulted from a long-term pattern of psychological trauma drawn from life experience (the field). However, by their very nature, traumatic memories can be difficult to access (Caruth 1995). To satisfy this test, I engaged in memory-evoking exercises to document as much of this experience as possible, sometimes surprising myself at the memories which surfaced. The second test for credibility is persistent observation, which measures if there has been an indepth pursuit of those elements found to be especially salient (2007: 18). The most significant element revealed by my data was the post-traumatic effect of dissociation. This led to an in-depth exploration of dissociation, which subsequently became the lens through which I told the story of my protagonist's experience of trauma in the creative component of the research.

While implementing these first two strategies for credibility legitimised my data, the potential for bias remained when I was the sole analyst of personal data collected over a prolonged period. To reduce this potential, two additional strategies-triangulation 
and peer debriefing-were introduced to achieve credibility. Triangulation requires cross-checking of data using varying sources, methods and if possible, investigators. As I was hypothesising a positive cognitive impact of writing about trauma as an 'insider' trauma survivor, a therapist was engaged as a second investigator to assess my mental/emotional state at the outset and at intervals during the research process to triangulate the investigation of the data. Confirmation of a positive cognitive impact is evidenced by one of the therapist's progress reports:

This process is challenging her perceptions and encouraging her to deal with her emotions on a more cognitive and objective level...[the researcher can now] differentiate between her memory of an emotion when recalling a traumatic event and experiencing the emotion in the present (personal correspondence: 1 December 2015).

Guba asserts that professional peer debriefing will 'keep the inquirer honest' (2007: 19). A narrative therapist was engaged to offer an expert opinion to substantiate my data analysis, or challenge it as the case required, through peer debriefing. The data was provided to the therapist in person and in the form of reflective journal entries, providing further triangulation in the source of the data, which emanated not only from my past but also from case studies of works by other trauma survivors. Methods including reflective practice and case study conventions were utilised to analyse the data, which further satisfied the test for credibility.

This strategy was also applied to the creative component of the thesis. Ellis suggests that 'validity means that our work seeks verisimilitude: it evokes in readers a feeling that the experience described is lifelike, believable and possible' (2003: 124). The data was provided to the narrative therapist in the creative format and an accompanying document mapping the research to the scenes in the creative work. Wood claims 'rigour can be defined as a state in which all the parameters of a given system are made explicit and can, therefore, be held in fixed relation to one another' (2012: 11). Table 1 demonstrates how the research into narrative strategies used to represent trauma and relevant trauma theory were applied to my creative work, which makes the parameters of the creative work explicit and shows their relation to one another.

\begin{tabular}{|c|c|c|}
\hline Literary Devices Used & Scenes & Research/Plot Development Notes \\
\hline Recurring water motif & Snippets of watery dream, how Flow almost drowned as a child. & $>$ Use of present tense - reflects that trauma recurs as \\
\hline Hook & Recalls her earliest memory of her sub-personality, Ebony. & if it is still happening in the present \\
\hline Fragmentation - textual gap & & $>$ Trigger used to segue into Ebb scene \\
\hline Intimacy - 2nd person child's persp. & The drowning incident told from Ebb's perspective. Father sneers and & $>$ Flow is silenced by father/childhood trauma. Only \\
\hline Fragmentation - textual gap & taunts Flow for her clumsiness. & Ebb recalls this trauma in the narrative. \\
\hline Mirroring & Charlie goes missing. Flow finds slipper outside bedroom. Searches & $>$ Trigger for Flow to re-live childhood trauma/aquaphobia \\
\hline Place as threatening & frantically, afraid she may have wandered down to the lagoon. & >Myths of landscape - water is not a safe place. \\
\hline Cliffhanger & $\begin{array}{l}\text { Justin goes looking for Charlie. Flow is left immobilised, contemplating } \\
\text { her secret aquaphobia, and how Ebb has always taken charge. }\end{array}$ & $\begin{array}{l}>\text { Lies and mental issues to paint Flow as unreliable } \\
\text { narrator, cast doubt about her part in disappearance }\end{array}$ \\
\hline Fragmentation - textual gap & & $>$ Trigger used to segue into Ebb scene \\
\hline Fragmentation - analepsis & Parents fighting, Flow escapes the house wishing for a better family. & $>$ Use of 'Family Romance' - longing for happy family \\
\hline Intimacy - 2nd person 'angsty teen' & $\begin{array}{l}\text { Ebb suggests she could run away or smother her father in his sleep } \\
\text { (first hint Ebony is 'bad' and may be able to influence Flow). }\end{array}$ & $\begin{array}{l}\text { >Pronoun 'you' stregthens depiction of dissociation } \\
\text { by conveying a sense of depersonalization and }\end{array}$ \\
\hline Fragmentation - textual gap & & creates illusory dialogical voice between Ebb and Flow \\
\hline
\end{tabular}

Table 1: Excerpt from research/scene map 
The narrative therapist was engaged to validate the authenticity of my creative writing by offering an expert opinion on whether the trauma research was enacted in the writing:

The first thing that came to mind as I read this paragraph was a curiosity about the father's attitude towards himself. How does an adult man come to the point in his life when he is sneering at the misadventure of his own 4-year-old child? No doubt you are familiar with the concept of Projection in psychology. Was all this outward hatred a manifestation of how he felt towards himself? (personal correspondence: October/November 2016)

Working with the therapist, who pointed out these connections between my past and my fictional writing that evaded me, enhanced my capacity to re-story events with verisimilitude in my creative work and avoid bias in my research voice. This technique could be adapted to other subject matter that relevant experts could examine.

Moving away from credibility, transferability may be achieved through 'thick descriptive data' (Guba 2007: 19) that provides context to allow findings to be applied elsewhere and 'offers a way to improve the lives of participants and readers' (Ellis 2003: 124). I endeavoured to satisfy this test by creating a transferable narrative that aims not only to benefit others who have been exposed to similar traumatic experiences, but also to provide lessons for writers who wish to understand how to represent trauma more effectively in their creative work.

Guba combines the tests for dependability and confirmability into a two-pronged audit of process and product (2007: 19). One method of auditing data to assess bias is to employ Chenail's quality control method, 'interviewing the investigator' (2011: 258), which entails assessing the instrument for collecting data and the integrity of the data obtained. In this case, questions were developed to guide the collection of data for the journaling and mapping processes. During my engagement with the therapist, my answers were analysed to identify any issues of avoidance or vulnerability, unrecognised feelings, or impressions that might lead to bias if unchecked. Therapists are experienced in detecting such states of mind, so their engagement in this role to interview insider researchers is an effective approach to avoid or adjust for the effects of bias as necessitated by Gerhard, and to provide a competent and objective external party to carry out the audit (Guba 2007: 19).

While it might be argued that doctoral supervisors could perform some of these roles, risks exist in the supervisory relationship resulting from the supervisor's empathic engagement with traumatised students and their reports of traumatic experiences. Dr Charles Figley claims that this can lead to 'an extreme state of tension and preoccupation with the suffering of those being helped to the degree that it can create a secondary traumatic stress for the helper' ("Did you know", 2015). This risk for the supervisor, ranging from compassion fatigue to vicarious traumatisation, could have detrimental effects on the supervisory relationship, the authenticity of the creative 
work, and the completion of the thesis. DaPra proposes that while it is impractical 'to surgically excise the emotional lives of writers from material being written' (2013: 3), or ask them to sanitise their work, many educators 'struggle to draw the line between instruction and counselling' (2013: 2) and become anxious and uncomfortable when interactions with students cross into the realm of therapy sessions. While Hecq decrees the benefits of a psychoanalytic pedagogy, this places the supervisor and student into an analyst/analysand position (2009: 41). She outlines some of the reservations of academics to enter this relationship, which include a lack of adequate training and generating a power disparity (2009: 43). In writing fictional accounts of trauma based on the student's past, it is inevitable that memories will be revealed, and imperative for the completion of the creative work and thesis that the merits of their use be analysed and incorporated into the writing process. This creates a dichotomy that needs to be resolved to maintain the authenticity of works produced and to adequately support students through to thesis completion. Engagement of a professional therapist to take on the role of counsellor is one way to resolve this dichotomy by removing the risk of traumatic stress for supervisors.

My supervisory team enabled this process by setting boundaries and roles at the beginning of the relationship, which included a process to refer me onto institutional professionals to explore any delicate subject matter and negative sequelae arising when dealing with traumatic material during the writing of the thesis. In maintaining these roles, my supervisors were free to focus on assessing the narrative and aesthetic merits of my writing, rather than getting caught up in the personal and sensitive nature of the subject matter and risking impairment to themselves and the supervisory relationship.

\section{Creativity}

\section{Identity}

Writers can choose, or be influenced, in how they perform as a writer based on the different perspectives they adopt. Ryan implies that a writer is an 'active designer of text, shaping meanings and expressing aspects of self within the social context' (2014: 131). This choice suggests that as a writer, I have a level of self-awareness of my different writing voices, but my performance of self in my writing can be influenced by subjective concerns such as skills, motivations, and experience. Furthermore, it can be conditioned by objective pressures such as social expectations and norms for 'correctness' (Archer 2007). Reflecting on my project, I had already placed a constraint on myself to fictionalise accounts of my traumatic experiences based on subjective concerns about 'correctness' for the sake of others involved, which may have had a bearing on whether I projected an authentic self into my writing or constrained my creative voice. Ryan (2014: 132) distinguishes between the authoritative voice, which conveys truth, and the resonant voice, which determines the relationship between the unconscious and the writing. The writer's identity is based on how the writer assumes these voices, so I had to address this, and any other constraints placed on me as a writer, either internal or external. 
Contexts may become further constrained if there is no outlet for negative responses to trauma. DaPra argues that beyond the initial cathartic effect of writing, 'the organizing, editing and structuring' (2013: 6) of the writing process results in cognitive restructuring, and the lasting benefit is in the ability of the trauma survivor to see the experience in a new light through the evolution of thought. DaPra similarly claims that 'working with a therapist can also help the writer to order the emotion' (2013: 5). Engaging professional assistance provides opportunities for students dealing with traumatic material to have psychological and emotional outlets, which may enable a more authentic self in their writing identity, leading to fewer inhibitions that stifle creativity and supress peripheral voices.

\section{Form}

In addition to an authentic self, creative practice-led research students may also struggle to maintain a creative self. This tension between creativity and the academic discipline is not new. In 2008, Krauth suggested that the effects of creating a novel for a doctorate program led to anxiety about both the creative process and the end product, and too much bureaucracy could impact upon the writer's freedom to create (Krauth 2008: xii). Tensions arise mostly in attempts by research students to satisfy both the accepted conventions of scholarship and their aims as creative practitioners to enhance their practice. In 2004, Milech and Schilo reported attitudes ranging from reticence and lack of confidence to outright hostility toward the prevailing methods of academic writing demanded of the exegetical component of the thesis (2004: 8). In more recent times, Brien et al claim that, although there have been improvements in students' acceptance and understanding of the purpose of this component of the research, the anxiety creative students experience in producing the exegetical component of the thesis has not dissipated (Brien et al. 2017). While inroads have been made tension still exists between creativity and the academic discipline. Brien has since developed a schema outlining the key and core components of an exegesis, recommending the use of an overall conventional structure that demonstrates that the creative practice falls within the accepted definitions of research and meets the criteria for assessment purposes (Brien et al. 2017).

Against this background of contention, the question that plagued me in designing my exegesis was how I would write a thesis with the daring to invent and the capacity to meet the long-guarded definitions of what conforms as academic research. Precedents for experimentation were explored by examining where others had ventured and ascertaining how this could inform the creativity of my exegesis and achieve my aims.

Michelle Crawford presents her exegesis in a non-conventional format in a selfconfessed 'effort to maintain both the human presence and the flow of a personal narrative within a suitably scholarly body of work' (2010: 193) as well as exploring 'the position of the writer/researcher inside that discipline, and the insecurities that influenced the development of both the fiction and exegetical work' (2010: 211). Many of my aims were reflected in Crawford's exegesis. Her format displays snippets of 
quotes, journal entries, samples of creative writing and notes that have resonated with her in a peripheral column alongside her principal scholarly text to 'engage with' and 'make visible' subtext that would typically remain unseen in a creative thesis (2010: 193). The fragmented nature of this form mirrored the narrative strategies of fragmentation I was using to represent trauma in my creative work. While I did not wish to mimic this form, it had an influence on my thinking of how to make the subtext of both the writer (through narrative strategies) and trauma survivor (through personal voice and story) visible in my exegesis through the use of the research/scene map, an excerpt of which was presented in Table 1 earlier. This opens a space for the writer's two subjective voices to be displayed. Crawford seeks to mirror the impetus for her creativity in her fictional work by merging her two selves into one: writer and researcher to writer/researcher. I adapted this model for my project to use personal voice to merge the identities of writer and trauma victim into 'a writer who was subjected to trauma' and also to mirror the impetus for my creative writing, which was to merge the two dissociated voices of the protagonist into a whole self.

Enza Gandolfo's exegesis takes personal voice a step further by making a clear demarcation between her two voices. In her 'search for a structure, form and language to illuminate the process of fiction-making in a theoretical context' (2004: 16), she divides her narrative into a dialogic exchange between two characters she names the Novelist and the Theorist (2004: 15). Both characters are represented visually in the format of a drama script. As my aim was to merge my two voices, I eventually discounted the use of the demarcated dialogical structure but retained the aim to bring the 'other into view' through the use of personal voice and story.

My aspiration was to design a thesis format that cultivated creative engagement between its two components. Taking on board the advice from Brien that the most important audience is the thesis' examiners (Brien et al. 2017), my final thesis structure was a slightly modified version of the conventional structure that allowed for the insertion of my parallel voices into the research alongside the use of a set of metaphors and themes shared with the creative work to bring the exegetical writing as close as possible to the creative impetus. This allowed the growth of the fiction to be interwoven with the growth of the author, while continuing to meet the definition and aims of academic research.

\section{Conclusion}

This article set out to explore concerns of the 'insider' researcher regarding how they can insert their peripheral voices and multiple identities into the creative thesis, particularly when dealing with traumatic subject matter, while paying attention to the tenets of rigour and the desire for creativity. Lessons have been drawn from the author's research practice that add support to the evolution of academic practices for creative writing-based methodological approaches. The preceding case study illustrates that validity concerns about the rigour of insider research may be overcome by adapting Guba's (2007) tests for the rigour of qualitative research, and that these may be extended to establish rigour in creative writing. Further methods have been 
offered to reconcile concerns surrounding innovation and maintenance of the creative self within the conventions of scholarship, and how the exegesis can be acceptably remodeled to have a more dynamic relationship with the creative writing component of the thesis while continuing to meet the definition and aims of academic research. These approaches may serve to ease some of the tensions faced by creative writer/researchers who seek to represent their multiple identities and sustain creativity in their research projects.

Works Cited List

Archer, M 2007 Making our way through the world: Human reflexivity and social mobility Cambridge: Cambridge University Press

Arnold, J 2005 'The PhD in writing accompanied by an exegesis' Journal of University Teaching and Learning Practice 2 (1), 36-50

Brien, DL, Owens, A, Pittaway, G, and Waters, I 2017 'Exegetical essentials: a framing structure and template for a comprehensive exegesis in the creative arts' TEXT 44, 1-18 Retrieved from http://www.textjournal.com.au/speciss/issue44/Brien et al.pdf

Caruth, C 1995 Trauma: Explorations in memory Baltimore: John Hopkins University Press

Chenail, RJ 2011 'Interviewing the Investigator: Strategies for Addressing Instrumentation and Researcher Bias Concerns in Qualitative Research' The Qualitative Report 16 (1), 255-262

Crawford, M 2010 Fingerprints: Exploration of Identity, Community and Place doctoral thesis, Murdoch University

DaPra, T 2013 'Writing Memoir and Writing for Therapy' Creative Nonfiction 48, 1-6 Retrieved from www.creativenonfiction.org/therapy-memoir

Davies, D and Dodd, J 2002 'Qualitative Research and the Question of Rigor' Qualitative Health Research 12, 279-289

Did you know? 2015 Retrieved from www.compassionfatigue.org/

Drake, P 2010 'Grasping at methodological understanding: a cautionary tale from insider research' International Journal of Research \& Method in Education 33 (1), 85-89

Ellis, C 2004 The Ethnographic I: A Methodological Novel about Autoethnography Walnut Creek: AltaMira Press

Gandolfo, E 2004 Swimming: Writing Childlessness, A Novel and Exegesis, Really Talking: Writing Illuminating Theory as Theory Illuminates Writing doctoral thesis, Victoria University, School of Communication, Culture and Languages, Faculty of Arts

Gerhard, T 2008 'Bias: Considerations for research practice' American Journal of Health-System Pharmacy 65, 2159-2168 
Hecq, D 2009 'Interactive Narrative Pedagogy as a Heuristic for Understanding Supervision in Practice-led Research' New Writing: The International Journal for the Practice and Theory of Creative Writing 6 (1), 40-50

Krauth, N 2008 'The Novel and the Academic Novel' in G Harper, and J Kroll (eds) Creative writing studies: Practice, research and pedagogy Clevedon, United Kingdom: Multilingual Matters Ltd, 10-20

Mays, N and Pope, C 1995 'Rigour and Qualitative Research' The BMJ 311, 109-112

Milech, BH \& Schilo, A 2004 “Exit Jesus': relating the exegesis and creative/production components of a research thesis' TEXT 3, 1-13

Retrieved from www.textjournal.com.au/speciss/issue3/milechschilo.htm

Ross, LE 2017 'An account from the inside: Examining the emotional impact of qualitative research through the lens of "insider" research' Qualitative Psychology, 4 (3), 326-327

Ryan, M 2014 'Writers as performers: Developing reflexive and creative writing identities' English Teaching: Practice and Critique 13 (3), 130-148

Schwandt, TA, Lincoln, YS and Guba, EG 2007 'Judging interpretations: But is it rigorous? trustworthiness and authenticity in naturalistic evaluation' New Directions For Evaluation 114, 11-25

Wood, J 2012 'In the cultivation of research excellence, is Rigour a No - Brainer?' Journal of Writing in Creative Practice 5 (1), $11-26$ 